\title{
Evaluation of chemotherapy response between Paclitaxel-Cisplatin, Paclitaxel -Gemcitabine and Gemcitabine - Cisplatin among non - resectable lung cancer patients, $A$ retrospective study in tertiary care hospital.
}

\author{
HO RASHID ${ }^{\mathrm{a}}, \mathrm{QE} \mathrm{ELAHI}^{\mathrm{b}}, \mathrm{MA}$ ALAM $^{\mathrm{c}}, \mathrm{F}^{\mathrm{SARKER}}{ }^{\mathrm{d}}$
}

\begin{abstract}
s:
Background: To compare the survival rate of paclitaxel plus cisplatin (PC arm), paclitaxel plus gemcitabine (PG arm) and gemcitabine plus cisplatin (GC arm) in chemotherapy patients with non resectable lung cancer.

Methods: This was a retrospective observational study to evaluate chemotherapy response among non resectable lung cancer patients with their survival at cancer center CMH, Dhaka since 01 July 2013 to 31 March 2015. One hundred fifty-four (154) non resectable lung cancer patients were randomly divided into three groups, 50 patients in $P C$ arm, 51 patients in $P G$ arm and 53 patients in GC arm. In PC arm paclitaxel $175 \mathrm{mg} / \mathrm{m} 2$ (day 1) with cisplatin $75 \mathrm{mg} / \mathrm{m} 2$ (day 1), in $P G$ arm Paclitaxel $175 \mathrm{mg} / \mathrm{m} 2$ (day 1) with gemcitabine $1000 \mathrm{mg} / \mathrm{m} 2$ (days 1 and 8) and in GC arm gemcitabine $1000 \mathrm{mg} / \mathrm{m} 2$ (days 1 and 8) with cisplatin 100mg/m2 (day 1 ).
\end{abstract}

Background:

Cancer is a leading cause of death worldwide, accounting for an estimated 9.6 million deaths in

a. Dr. (Lt. Col.) Md. Harun-or-Rashid, Combine Military Hospital (CMH) Dhaka-1206.

b. Dr. (Brig. Gen.) Quadrat-E-Elahi, Combine Military Hospital (CMH) Dhaka-1206.

c. Dr. (Maj) Md. Ashraful Alam, Combine Military Hospital (CMH) Dhaka-1206.

d. Dr. (Maj) Fatima Sarker, Combine Military Hospital (CMH) Dhaka-1206.

Adddress of Correspondence: Dr. (Lt. Col.) Md. Harun-or-Rashid, Combine Military Hospital (CMH) Dhaka-1206, E-mail: imharunr@gmail.com, Cell: 01819167268
Results: Patients characteristics were similar between the three groups. The overall response rate was $40 \%$ in the $P C$ arm, $43.1 \%$ in the $P G$ arm, 43.4\% in the GC arm. The median survival time in PC arm was 8.5 months, in PG arm was 8.8 months, in GC arm was 9.2 months. The major side effect was myelosuppression which accounts $71 \%$ patients. The average treatment costs were $57 \%$ and $30 \%$ lower in PC arm as compared with $G C$ and $P G$ arm respectively.

Conclusion: The median survival time, disease free survival time and 1-year survival rate in PC, PG, $G C$ arms without significant difference. Treatment were well tolerable; quality of life parameter was mostly similar but paclitaxel with cisplatin was most cost effective than others chemotherapy regimen.

Keywords: Non-resectable lung cancer, Paclitaxel, Gemcitabine, Cisplatin, CMH.

(J Bangladesh Coll Phys Surg 2020; 38: 172-175)

DOI: https://doi.org/10.3329/jbcps.v38i4.48977

$2018^{[1]}$. Lung cancer has been the most common cancer in the world since 1985 and the leading cause of cancer death approximately 1.76 million deaths. There are about one million cancer patients in Bangladesh, with about 0.2 million patients newly diagnosed with cancer each year ${ }^{[2]}$. As of 2018, in Bangladesh out of all cancer patients, $8.2 \%$ is newly diagnosed with Lung Cancer, the number might seem insignificant but that is about 12,374 people ${ }^{[3]}$. Lung carcinoma is the most common cause of death from malignant disease in Western countries ${ }^{[4]}$. Relief of symptoms and a resultant improvement in quality of life may be achieved in many patients treated with chemotherapy ${ }^{[5]}$. Gemcitabine, Cisplatin and Paclitaxel are among the most active agents available for the treatment of lung cancer with different mode of action. Each has been shown to produce objective 
response in previously untreated patients with advanced or metastatic stages and to improve survival and quality of life when compared to best supportive care. This was a retrospective observational study to evaluate chemotherapy response among non resectable lung cancer patients with their survival at cancer center CMH, Dhaka since 01 July 2013 to 31 March 2015. The aim of this study was to compare evaluate the efficacy, feasibility, safety and their survival of the three commonly used chemotherapy regimen between Paclitaxel-Cisplatin, PaclitaxelGemcitabine and Gemcitabine- Cisplatin in patients with non resectable lung cancer. Tobacco control and smoking cessation remain the most important long-term intervention to decrease morbidity and mortality from lung cancer patients in Bangladesh. This study also describes economic benefits treatment for non resctable lung cancer patients in Bangladesh. Detailed long-term study could have shown some significant difference among the quality of life and recurrence of disease.

\section{Methodology:}

A total number of 154 lung cancer patients of $\mathrm{CMH}$ Dhaka from the period of 2013 to 2015 were randomly assigned to a regimen PC (PaclitaxelCisplatin), GP(Paclitaxel-Gemcitabine), GC(GemcitabineCisplatin). 50 Patients were randomly assigned to receive paclitaxel $175 \mathrm{mg} / \mathrm{m}^{2}$ (day 1) with cisplatin $75 \mathrm{mg} / \mathrm{m}^{2}$ (day 1), 51 patients receive Paclitaxel 175 $\mathrm{mg} / \mathrm{m}^{2}$ (day 1) with gemcitabine $1000 \mathrm{mg} / \mathrm{m}^{2}$ (days 1 and 8) and 53 patients receive gemcitabine 1000 $\mathrm{mg} / \mathrm{m}^{2}$ (days 1 and 8) with cisplatin $100 \mathrm{mg} / \mathrm{m}^{2}$ (day 1). Efficacy, toxicities and chemotherapy response were assessed, analyzed and compared with Analysis of Variance (ANOVA).

\section{Results:}

148 Patients among 154 who had cancer were over 45 years old, which accounts for $96.1 \%$ of the total number of patients. Total number of male patients was 124 and 30 patients were female. 105 Patients among 154 were smokers, which accounts for $68.2 \%$ of the total number of patients. Patients had previously untreated lung cancer, measurable diseases, performance status $\leq 2$ and no brain metastases. In this study total number of patients 154 who has been suffering from four types of lung cancer adenocarcinoma (52), squamous cell carcinoma (47), non-small cell lung cancer (NSCLC) (37) and small cell lung cancer (SCLC) (18).
Table 01: Types and total one hundred fifty-four lung cancer patients

\begin{tabular}{|c|c|c|}
\hline Type of cancer & Frequency & Percentage \\
\hline Adenocarcinoma & 52 & $33.8 \%$ \\
\hline Squamous cell carcinoma & 47 & $30.5 \%$ \\
\hline NSCLC & 37 & $24.0 \%$ \\
\hline SCLC & 18 & $11.7 \%$ \\
\hline
\end{tabular}

Table 02: Percentage of patients suffering Co-existing diseases.

\begin{tabular}{|c|c|}
\hline Co-Existing Disease Name & Percentage \\
\hline Diabetes mellitus (DM) & $16.0 \%$ \\
\hline Hypertension (HTN) & $21.0 \%$ \\
\hline Chronic kidney disease (CKD) & $6.0 \%$ \\
\hline Chronic obstructive pulmonary Disease (COPD) & $24 \%$ \\
\hline Ischemic heart disease (IHD) & $11.0 \%$ \\
\hline Cardiovascular disease (CVD) & $6 \%$ \\
\hline Others & $11 \%$ \\
\hline
\end{tabular}

Table 02 shows highest numbers of patients were suffering from Chronic obstructive pulmonary Disease (COPD) which accounts for $24 \%$ of the total number of patients, Hypertension (HTN) 21.0 $\%$, Diabetes mellitus (DM) $16.0 \%$, Ischemic heart disease (IHD) $11.0 \%$ and Chronic kidney disease (CKD) $6.0 \%$.

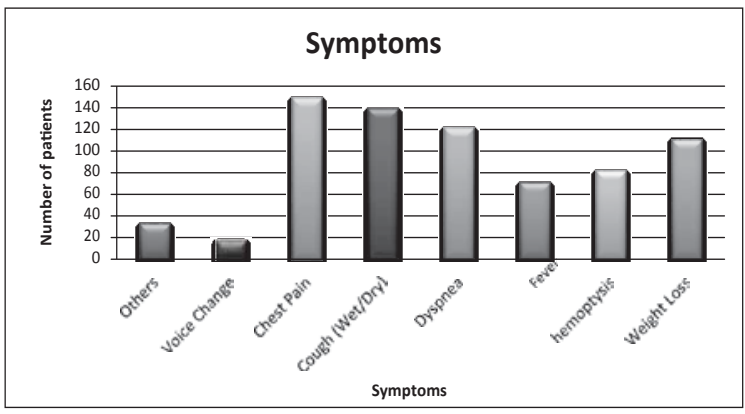

Figure 01: Symptoms of patients

Figure 01 shows 149 Patients among 154 reported chest pain, which accounts for $96.75 \%$ of the total number of patients. Others symptoms are cough (90\%), dyspnea (79\%), weight loss (72\%), hemoptysis $(53 \%)$, fever $(46 \%)$, voice change $(11 \%)$ and others $(33 \%)$. 
1 Year Survival Rate among Chemotherapy Regimens:
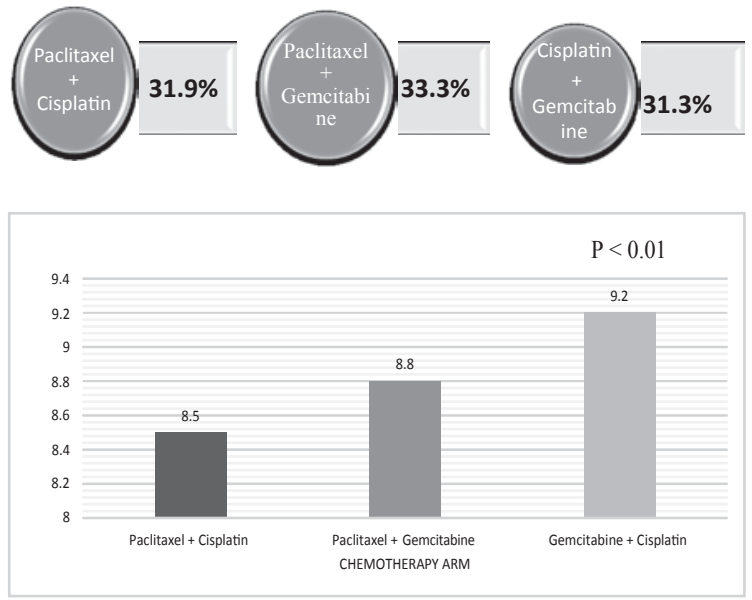

Figure 02: Median survival rate among chemotherapy regimens at $\mathrm{CMH}$.

Figure 02 shows the median survival time in $\mathrm{PC}$ arm 8.5 months, in PG arm 8.8 months, in GC arm 9.2 months. Disease free survival were 4.1 months, 3.8 months,3.9 months respectively in PC, PG, GC arms. One-year survival rate were $31.9 \%$ in $\mathrm{PC}$ arm, $33.33 \%$ patients in $\mathrm{PG}$ arm and $31.3 \%$ in GC arm without any significant difference. The response rates were $40 \%$ (20 out of 50 Patients) in PC arm, 43.1\% (22 out of 51 Patients) in PG arm and 43.4\% (22 out of 53) in GC arm and complete remission rates were $1.0 \%$ in $\mathrm{PC}$ arm, $2.2 \%$ in $\mathrm{PG}$ arm and $2.2 \%$ in GC arm. This result is statistically significant $(\mathrm{P}<0.01)$.

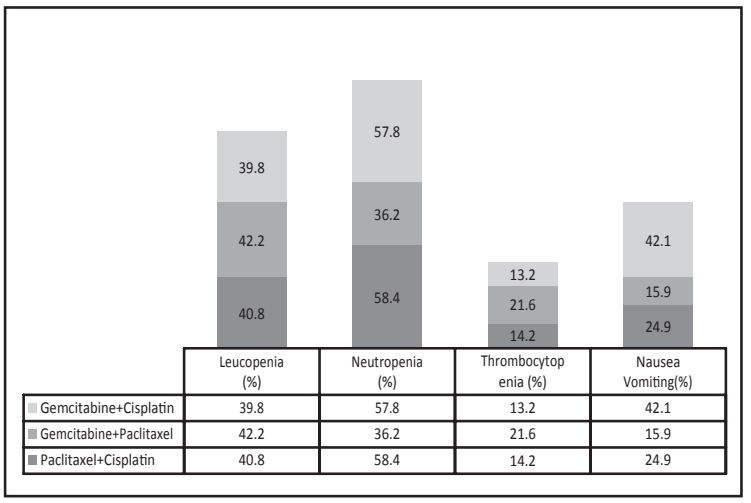

Figure 03: Percentage of major side effects

Figure 03 shows that major side effect was myelosuppression 110 Patients among 154 had these symptoms. There were highest incidences of leucopenia (42.2\%), neutropenia (36.2\%) and lowest incidence of thrombocytopenia (21.6\%) in PG arm compared to in GC arm $(39.8 \%, 57.8 \%, 13.2 \%)$ and in PC arm $(40.8 \%, 58.4 \% 14.2 \%)$. The rate of nausea/ vomiting in $\mathrm{PG}$ arm $(15.9 \%)$ and $\mathrm{PC}$ arm $(24.9 \%)$ were significantly lower than GC arm (42.1\%).

Table 03: Adverse effects

\begin{tabular}{|c|c|c|}
\hline Adverse effects & Frequency & Percentage \\
\hline Anorexia & 91 & $59.09 \%$ \\
\hline Weakness & 83 & $53.89 \%$ \\
\hline Diarrhea & 81 & $52.59 \%$ \\
\hline Constipation & 74 & $48.05 \%$ \\
\hline Myalgia & 53 & $34.41 \%$ \\
\hline Leg edema & 39 & $25.32 \%$ \\
\hline Arthralgia & 27 & $17.53 \%$ \\
\hline Others & 23 & $14.93 \%$ \\
\hline
\end{tabular}

\section{Discussion:}

It is important to realize that patients with stage I NSCLC may already have small amounts of cancer that have spread outside the lung and cannot be detected with any of the currently available tests. A National Cancer Institute of Canada clinical trial showed that adjuvant chemotherapy for stage I NSCLC increased the number of patients who lived 5 years or more from $54 \%$ to $69 \%{ }^{[6]}$ and US researchers have demonstrated that adjuvant chemotherapy increased the number of patients who survived 3 years or more from $69 \%$ to $82 \%{ }^{[7]}$. Stage IV non-small cell lung cancer (NSCLC) is the most advanced form of the disease. In stage IV, the cancer has metastasized, or spread, beyond the lungs into other areas of the body. About 40 percent of NSCLC patients are diagnosed with lung cancer when they are in stage IV. The five-year survival rate for those diagnosed with stage IV lung cancer is less than 10 percent ${ }^{[8]}$. A total number of 154 patients (Arm PC, 50; Arm PG,51; Arm GC,53;) all baseline characteristics were balanced and enrolled. The overall survival rate 8.5 months, 8.8 months, 9.2 months respectively in PC, PG and GC arm which is mostly similar on phase III trial of the European Organization for research and treatment of lung cancer group ${ }^{[9]}$. Among three arms cost effectives is much better or superior in PC arm compared to GC 
and PG arm. The overall cost of a patient in PC arm chemotherapy regimen per cycle $13313 \pm 1000$ (BDT), in PG arm $29405 \pm 1200$ (BDT), in GC arm $30131 \pm 1500(\mathrm{BDT})$. The average treatment costs were $59.85 \%$ and $58.71 \%$ lower in $\mathrm{PC}$ arm as compared with GC and $\mathrm{PG}$ arm respectively. The major adverse reactions were myelo-suppression, vomiting, nausea, anorexia and weakness. The major incidence was leucopenia, neutropenia and thrombocytopenia. GC arm shows enormous side effects compared with others two arms. Whereas PC arm shows less side effects then GC arm but a bit more from PG arm. The median survival time, disease free survival time and 1-year survival rate in PC, PG, GC arms without significant difference.

\section{Recommendation:}

At the end of this study we can adhere with PC arm in the treatment of non resectable lung cancer in view of the cost effectiveness, overall survival rate and its acceptable side effects.

\section{Conclusion:}

There is no significant difference in short-term efficacy of chemotherapy regimen PC, PG, GC. Gemcitabine plus cisplatin and paclitaxel plus gemcitabine do not increase significantly overall survival in patients with non resectable lung cancer as compared with paclitaxel plus cisplatin. Paclitaxel plus cisplatin are most cost effective than other chemotherapy regimens. A more detailed long-term study could have shown some significant difference among the quality of life and recurrence of disease.

\section{References:}

1. Ferlay J, Soerjomataram I, Dikshit R, Eser S, Mathers C, Rebelo M, Parkin DM, Forman D, Bray F. Cancer incidence and mortality worldwide: sources, methods and major patterns in GLOBOCAN 2012. International journal of cancer. 2015 Mar 1;136(5):E359-86. [Google Scholar].

2. Backert MS. Applied immunoinformatics: HLA peptidome analysis for cancer immunotherapy. [Google Scholar].
3. A One-Year Report, Parveen Shahida Akhtar, Journal of Medicine ISSN 1997-9797; elSSN 2075-5384; Profile of Lung Cancer.

4. Rodriguez J, Cortes J, Calvo E, Azinovic I, Fernandez-Hildago O, Martinez-Monge R, Garzon C, de Irala J, Martinez-Aguillo M, Ramon y Cajal T, Brugarolas A. Paclitaxel, cisplatin, and gemcitabine combination chemotherapy within a multidisciplinary therapeutic approach in metastatic nonsmall cell lung carcinoma: A Phase II study. Cancer. 2000 Dec 15;89(12):2622-9.

5. Grilli R, Oxman AD, Julian JA. Chemotherapy for advanced non-small-cell lung cancer: how much benefit is enough?. Journal of clinical oncology. 1993 Oct;11(10):1866-72.

6. Strauss GM, Herndon J, Maddaus MA, et al. Randomized clinical trial of adjuvant chemotherapy with paclitaxel and carboplatin following resection in Stage IB non-small cell lung cancer: Report of Cancer and Leukemia Group B (CALGB) Protocol 9633. Journal of Clinical Oncology. 2004;22:Suppl 14S: Abstract \#7019.

7. The International Adjuvant Lung Trial Collaborative Group. Cisplatin-based adjuvant chemotherapy in patients with completely resected Non-Small Cell Lung Cancer. New England Journal of Medicine. 2004;350:351-360

8. Cancer treatment Centre in America (2020) https://www.cancercenter.com/cancer-types/lung-c ancer/stages\#: :text=In\%20stage\%20IV\%2C\%20the \%20cancer, is\%20less\%20than\%2010\%20percent. (Excess Date:2020)

9. Smit EF, Van Meerbeeck J, Lianes P, Debruyne C, Legrand C, Schramel F, Smit H, Gaafar R, Biesma B, Manegold C, Neymark N. Three-arm randomized study of two cisplatin-based regimens and paclitaxel plus gemcitabine in advanced non-small-cell lung cancer: a phase III trial of the European Organization for Research and Treatment of Cancer Lung Cancer Group-EORTC 08975. Journal of Clinical Oncology. 2003;21(21):3909-17. [PubMed] [Google Scholar] 